\title{
Interprofessional Education as a Need: The Perception of Medical, Nursing Students and Graduates of Medical College at King Abdulaziz University
}

\author{
Hind Ibrahim Fallatah1 ${ }^{*}$, Razan Jabbad2, Heba K. Fallatah ${ }^{3}$ \\ ${ }^{1}$ Department of Internal Medicine, King Abdulaziz University, Jeddah, Saudi Arabia \\ ${ }^{2}$ Faculty of Medicine, King Abdulaziz University, Jeddah, Saudi Arabia \\ ${ }^{3}$ King Abdulaziz University Hospital, Jeddah, Saudi Arabia \\ Email: ${ }^{*}$ hindfallatah@hotmail.com, ${ }^{*}$ hfallatah@kau.edu.sa
}

Received 5 February 2015; accepted 23 February 2015; published 26 February 2015

Copyright (C) 2015 by authors and Scientific Research Publishing Inc.

This work is licensed under the Creative Commons Attribution International License (CC BY).

http://creativecommons.org/licenses/by/4.0/

(c) (i) Open Access

\section{Abstract}

Interprofessional education (IPE) is when members or students of two or more professions learn from and about each other to improve collaboration and quality of care. The aim of this study was to identify the awareness and importance of IPE among medical and nursing students and graduates at King Abdulaziz University. A cross-sectional study was conducted with fourth-year medical students, fourth-year nursing students, interns, and internal medical residents at King Abdulaziz University and hospital. A survey was completed by all the participants after they gave their consent. Participants were asked whether they knew the meaning of IPE. We explained IPE to those who did not know what it was. Then, each participant was asked to rate all 11 items on the survey with one of five choices: strongly agree, agree, undecided, disagree and strongly disagree. A total of $\mathbf{1 0 5}$ professionals participated in the study. The participants were primarily fourth-year medical and nursing students, all of whom were women. However, for the medical interns and medical residents, we included both men and women. Only $12(11.4 \%)$ participants knew the meaning of IPE, all of whom were medical residents. The majority-77 of $103(75 \%)$, most of whom were nursing students-responded that IPE is important. The difference between the groups was also significant $(P=\mathbf{0 . 0 0 8})$. In conclusion: Our study showed that our medical students and graduates valued IPE and thought that the implementation of IPE in their education would improve both patient care and health care provider satisfaction.

\footnotetext{
${ }^{*}$ Corresponding author.
} 


\section{Keywords}

\section{Medical Students, Nursing Student, Interprofessional Education, King Abdulaziz University}

\section{Introduction}

Interprofessional education (IPE) is defined by the UK Centre for the Advancement of Interprofessional Education (CAIPE) as the occasion when members or students of two or more professions learn from and about each other to improve collaboration and quality of care (Blue et al., 2010; Buring et al., 2009; Hammick et al., 2007; Levisohn, 2003; Oandasan et al., 2005; Olenick et al., 2010). IPE is also defined as a teaching and learning process that fosters collaborative work and improves quality of care between two or more professions. The Canadian Interprofessional Health Collaboration (CIHC) adds that IPE occurs when health care professions learn collaboratively within and across disciplines to acquire knowledge, skills and values for working in teams (Canadian Interprofessional Health Collaborative (CIHC), 2014). IPE is different from multi-professional education or shared and common learning (An RCN Literature Review, 2007).

IPE was promoted in 1988 by the World Health Organization (WHO) through two reports on continued education for physicians learning to work together to improve health care (Barr, 2002; Hammick et al., 2007; Thistle Thwaite, 2012). The WHO has continued supporting IPE, and most recently, it published the framework for Action on Interprofessional Education \& Collaborative Practice in 2010.

The importance of IPE came from the need for health care team members who provide high-quality care in the most collaborative and competent way (Hall et al., 2001; WHO, 2014). Each member of a health care team needs to understand the role of other members from different professions using appropriate communication and conflict-management skills (Hall et al., 2001; Lumague et al., 2006). Furthermore, the aging society, the increase in chronic illnesses and patients in need of complex care, and rapidly evolving scientific knowledge necessitate interprofessional collaborations for optimal patient care (Lumague et al., 2006; Thistle Thwaite, 2012; WHO, 2014).

Another important driving factor for IPE is that it is an important accreditation standard or recommendation guideline for different health care professional education national and international accreditation bodies and councils (Buring et al., 2009; Julio et al., 2010; Canadian Interprofessional Health Collaborative (CIHC), 2014; Thistle Thwaite, 2012).

IPE has been shown to be effective at learner levels, patient care levels and organizational levels (Hammick, 2000; Horsburgh et al., 2001; Humphris, 2007; Remington et al., 2006).

Compared with traditional education, IPE has been found to enable the knowledge and skills necessary for collaborative teamwork (Hammick et al., 2007; Hammick, 2000).

IPE is effective in teaching students the roles of other health care professions and changing students' attitude towards them (Horsburgh et al., 2001; Humphris, 2007; Lumague et al., 2006; Mires et al., 2001; Ponzer et al., 2004; Remington et al., 2006; WHO, 2014).

IPE increases job satisfaction and decreases workplace tension and conflict (Hammick, 2000; Ponzer et al., 2004).

IPE has also been found to have a positive effect on patient care, patient and family satisfaction, patient safety and error rates (Buring et al., 2009; Hammick, 2000; Hammick, 2006; Ponzer et al., 2004; Reeves et al., 2013).

IPE is cost-effective and leads to savings by reducing the use of services, leading to less redundancy in medical testing. IPE has positively affected the appropriate use of health resources and increased the use of preventive services (Hammick, 2000; WHO, 2014).

In Saudi Arabia, the number of health care education centers and colleges is rapidly developing and increasing. Furthermore, the number of patients with chronic illnesses (like diabetes) who need health care professionals' interaction and collaboration is increasing. Additionally, several outbreaks of serious infections have been increasingly recognized during the Hajj and Omra seasons, calling for the need for efficient health care personnel interactions during patient care (Al-Nozha et al., 2004; Middle East Respiratory Syndrome Coronavirus (MERS-CoV)—Saudi Arabia, 2014).

The aim of this study was to identify the awareness and importance of IPE among fourth-year medical and nursing students and medical interns and residents at King Abdulaziz University's medical and nursing colleges and King Abdulaziz University Hospital. 


\section{Methods}

This was a cross sectional study.

This work was carried out as an activity with the Master's of Medical Education program (a collaborative program between UIC and KAU) that has the approval of the medical faculty and King Abdulaziz University. The fourth year of the medical program is the first clinical year; the students practice on real patients in a hospital context. In the school of nursing, the fourth year is the final year of the program, and students are taught both in the hospital and on campus. The medical interns are graduates of the school of medicine (both males and females) who have received a diploma and are rotating in their mandatory internship year in hospital-based training. Internal medicine residents (both males and females) are residents in the 4-year Saudi internal medicine training program.

Study population: Fourth-year medical students (all females), fourth-year nursing students (all females), interns completing an internal medicine rotation, and internal medical residents at King Abdulaziz University and King Abdulaziz University Hospital, Jeddah.

Data were collected by two research team members, one intern and one resident. The meanings and spectrum of IPE were explained thoroughly to the participants. Then, a survey in the form of a questionnaire was completed by all of the participants after they had consented to participating. The survey was conducted as follows. Each candidate was asked if he/she knew the meaning of IPE; if he/she did not, we explained it. Then, each candidate was asked to rate all 12 items on the survey with one of five possibilities: strongly agree, agree, undecided or not sure, disagree or strongly disagree. The items were as follows:

1) Learning with other health care students will make me a more effective member of health care and social teams.

2) Patients will ultimately benefit in health and social care if students learn together.

3) Communication skills should be taught and learned with other health care students.

4) Teamwork skills are vital for all health care students.

5) Learning clinical skills together before qualification will improve the work environment.

6) Some of the communication skills that are related to patients' safety should be taught to medical and nursing students together.

7) Respecting other health care students is essential for IPE to be effective.

8) IPE for medical and nursing students is a waste of time.

9) It is not necessary for medical and nursing student to learn together.

10) I would welcome the opportunity to learn clinical skills with other health care students.

11) IPE before qualification will help me to be a better team worker.

The last Item was: "If you think IPE is important, what level of medical and nursing education is the appropriate time to apply it?” For this item, medical students, nursing students and interns were given 5 options: preclinical years, clinical years, at both preclinical and clinical years, internship, and the time is not important. Internal medicine residents were given all 5 options and an additional option about IPE during residency.

The survey was completed and collected over 2 days, February 11-12, 2014.

\section{Results}

A total of 107 participants agreed to complete the questionnaire. Two candidates—one resident and one fourthyear medical student-turned in an incomplete form with missing items; they were excluded from the analysis. The remaining 105 participants were primarily fourth-year medical and nursing students, as shown in Table 1 . We included only female medical students to be comparable to the nursing students, who were all females; however, for the medical interns and medical residents, we included both males and females ( $50 \%$ each). Only 12 (11.4\%) candidates knew the meaning of IPE, all of whom were medical residents; the remaining 93 (88.6\%) subjects had no idea what IPE was. The majority—77 of 103 (75\%) — responded that IPE is important for the health care profession during their education as shown in Table 2. All 40 nursing students (100\%) either strongly agreed or agreed that IPE is important, whereas 16 (64\%) medical students, 13 (68.4\%) interns and 8 (38\%) residents either strongly agreed or agreed that IPE is important Table 2 and Figure 1. The difference between the participants of the three medical levels and the nursing students was significant according to the chi-squared test $(P=0.001)$, and the difference between all the groups was also significant $(P=0.008)$. This finding was also supported by the responses to the item regarding whether IPE was a waste of the participants' 
Table 1. Number and percentage of participants according to academic level.

\begin{tabular}{ccc}
\hline Category of participants & Number & Percent \\
\hline Residents & 21 & 20.0 \\
Interns & 19 & 18.1 \\
Nursing students & 40 & 38.1 \\
Medical students & 25 & 23.8 \\
Total & 105 & 100.0 \\
\hline
\end{tabular}

Table 2. Participants' responses to the first 11 items of the survey.

\begin{tabular}{|c|c|c|c|c|c|}
\hline & Strongly agree & Agree & Not sure & Disagree & Strongly disagree \\
\hline $\begin{array}{l}\text { 1) Learning with other health } \\
\text { care student will make me a } \\
\text { more effective member of health } \\
\text { care and social teams. }\end{array}$ & 41 (39\%) & 47 (44.8\%) & $9(8.6 \%)$ & $6(5.7 \%)$ & $2(1.9 \%)$ \\
\hline $\begin{array}{l}\text { 2) Patients will ultimately } \\
\text { benefit in health and social care } \\
\text { if students learn together. }\end{array}$ & $26(24.8 \%)$ & 49 (46.7\%) & $21(20 \%)$ & $8(7.6)$ & $1(1 \%)$ \\
\hline $\begin{array}{l}\text { 3) Communication skills should } \\
\text { be taught and learned with other } \\
\text { health care students. }\end{array}$ & 48 (45.7\%) & 46 (43.8\%) & $6(5.7 \%)$ & $5(4.8 \%)$ & 0 \\
\hline $\begin{array}{l}\text { 4) Teamwork skills are vital for } \\
\text { all health care students. }\end{array}$ & $54(51.4 \%)$ & 44 (41.9\%) & $5(4.8 \%)$ & $2(1.9 \%)$ & 0 \\
\hline $\begin{array}{l}\text { 5) Learning clinical skills } \\
\text { together before qualification } \\
\text { will improve the work } \\
\text { environment. }\end{array}$ & $36(34.3 \%)$ & $51(48.8 \%)$ & $8(7.6 \%)$ & $10(9.5 \%)$ & 0 \\
\hline $\begin{array}{l}\text { 6) Some of the communication } \\
\text { skills that are related to patients' } \\
\text { safety should be taught to } \\
\text { medical and nursing students } \\
\text { together. }\end{array}$ & $34(32.4 \%)$ & 49 (46.7\%) & $14(13.3 \%)$ & $7(6.7 \%)$ & $1(1 \%)$ \\
\hline $\begin{array}{l}\left.{ }^{*} 7\right) \text { Respect and trust are } \\
\text { essential for IPE to be effective. } \\
103 \text { respondents }\end{array}$ & 59 (56.2\%) & 42 (40\%) & $1(1 \%)$ & $1(1 \%)$ & 0 \\
\hline $\begin{array}{l}\text { 8) IPE for medical and nursing } \\
\text { students is a waste of time. }\end{array}$ & $4(3.8 \%)$ & $12(11.4 \%)$ & 25 (23.8\%) & $46(43.8 \%)$ & $18(17.1 \%)$ \\
\hline $\begin{array}{l}\text { 9) It is not necessary for medical } \\
\text { and nursing students to learn } \\
\text { together. }\end{array}$ & $5(4.8 \%)$ & $17(16.2 \%)$ & $23(21.9 \%)$ & $47(44.7 \%)$ & 13 (12.4\%) \\
\hline $\begin{array}{l}\left.{ }^{* *} 10\right) \text { I would welcome the } \\
\text { opportunity to learn clinical } \\
\text { skills with other health care } \\
\text { students. } \\
103 \text { respondents }\end{array}$ & 28 (26.7\%) & 49 (46.7\%) & 10 (9.5\%) & 15 (14.3\%) & $1(1 \%)$ \\
\hline $\begin{array}{l}\left.{ }^{* * *} 11\right) \text { IPE before qualification } \\
\text { will help me to be a better team } \\
\text { worker. }\end{array}$ & 32 (30.5\%) & $56(53.3 \%)$ & $13(2.4 \%)$ & $2(1.9 \%)$ & 0 \\
\hline
\end{tabular}

${ }^{*} 2$ candidates did not respond to item $7 ;{ }^{* *} 2$ candidates did not respond to item $10 ;{ }^{* * *} 2$ candidates did not respond to item 11. 


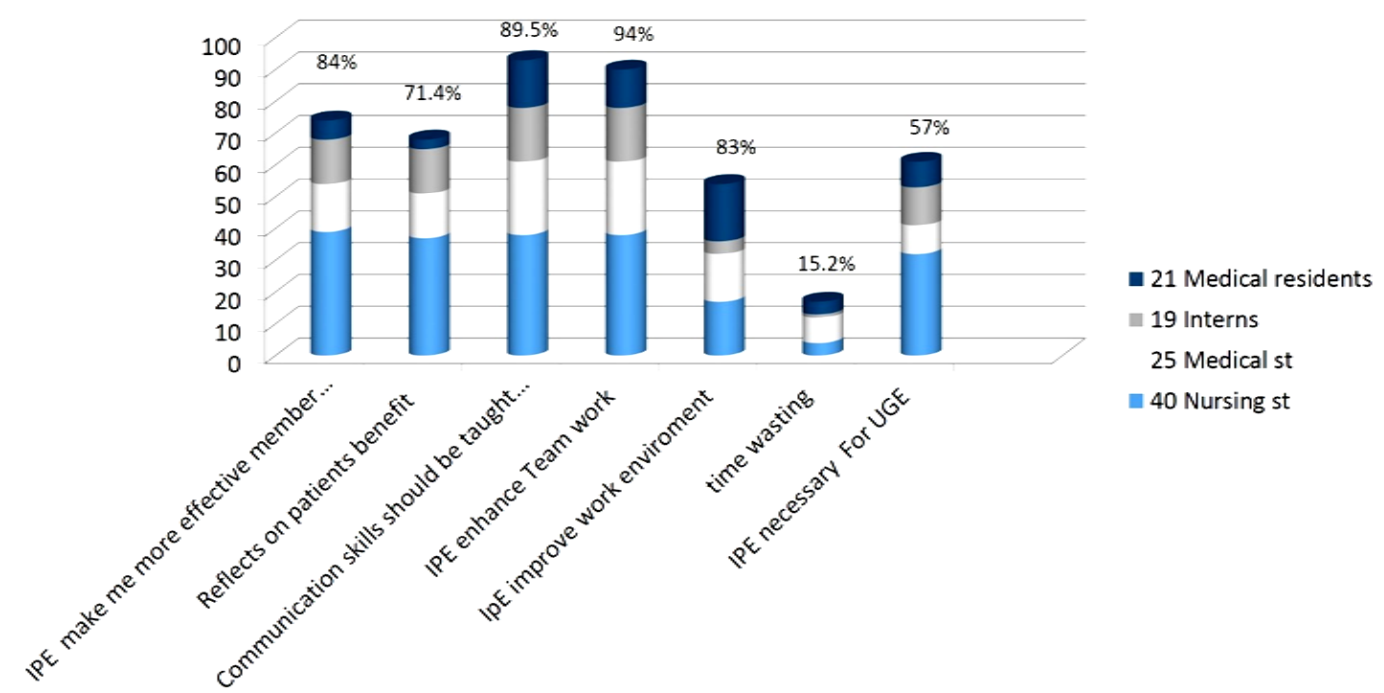

Figure 1. Result of survey about Interprofessional education among KAU medical and nursing students and medical graduates.

time; only 12 (18.5\%) of all medical participants and 4 (10\%) of nursing participants strongly agreed or agreed that IPE was a waste of their time.

There was a difference between the different groups of participant with respect to the suggested levels of implementation: 18 (45\%) nursing students thought that the IPE is best during the internship for both medical and nursing students, whereas 9 (36\%) of medical students thought that IPE is best during the clinical years of education $(P=0.014)$ between all the groups.

\section{Discussion}

Our study showed two main findings. The first finding is that the majority of our medical and nursing graduates do not understand what IPE is; this by itself is important because the interaction between the medical and nursing student starts in the obligatory internship year, immediately after graduation. During the internship year, there is actual interaction with other health care providers. This finding is important because IPE is an internationally recognized term and is implemented by various accreditation bodies as a standard for the accreditation of health science colleges (Blue et al., 2010; Buring et al., 2009, Hammick et al., 2007; Levisohn, 2003; Oandasan et al., 2005; Olenick et al., 2010). However, we did not come across any paper that addressed IPE among health care students from Saudi Arabia or from the gulf region. The second important finding from our study is that, after explaining to the participants the meaning of IPE, most of the participants highly valued IPE and agreed to have IPE classes that include medical and nursing student during their college education. This is, again, important because King Abdulaziz University is a leading university in Saudi Arabia that helps establish multiple health care colleges in other national universities. Along with other national and regional health care colleges, King Abdulaziz University may need to consider developing IPE programs in their current updated curricula. Students' perception of the effectiveness of IPE in improving teamwork abilities and communication skills has been shown previously in several studies from several countries (Hall et al., 2001; Hammick, 2006; WHO, 2012). Furthermore, and similar to our student expectations, IPE has been shown to have a positive effect on patient care and outcomes and to influence the satisfaction of both patients and their families (Buring et al., 2009; Hammick, 2006; Hammick, 2000; Ponzer et al., 2004; Reeves et al., 2013). The positive expectations of our students support the need for IPE in our health care colleges, particularly medical and nursing colleges, and particularly because the graduates of those two colleges interact most of the time in real patient care practice. We found that all of the nursing students were more supportive of IPE, but among medical students, there was a difference according to academic level; this difference between students may reflect their level of knowledge and differences in the curriculum load between the medical and nursing college students. Another reason might be due to the elevated social and cultural recognition of doctors' professional identity over that of nurses', which has been shown by previous studies (Barker et al., 2005; Mandy et al., 2004). It is notable that only a few stu- 
dents thought that IPE would be a waste of their time, even among medical students, who have a busy curriculum. Participants in our cohort suggested different levels for the implementation of IPE, but most of them agreed that IPE during the clinical years of education is essential. Previous reports have suggested that the appropriate timing for implementation is essential for the effectiveness of IPE (Bridges et al., 2011; Hojat et al., 2001; Sweet et al., 1995). As a new program, the implementation of IPE in an institution will require preparation and arrangements between the administrations of both the medical and the nursing colleges, curriculum program developers from both colleges and full institutional support. A pilot implementation will help to determine the weaknesses in the program prior to full implementation (Barr, 2002; Blue et al., 2010; Buring et al., 2009; Hall et al., 2001; Hammick et al., 2007; Humphris, 2007; Levisohn, 2003; Olenick et al., 2010).

\section{Limitations of the Study}

1) Most of the participants were of $4^{\text {th }}$ year medical and dental students and other levels of students like $5^{\text {th }}$ and $6^{\text {th }}$ year medical students were not included, that group might have different perception because of busier curriculum compared to $4^{\text {th }}$ year students.

2) Similarly nursing interns and graduated practicing nurses were not included and again they might have different perception about IPE.

\section{Conclusion}

Our study showed that our medical student and graduates valued IPE and thought that the implementation of IPE in their education would improve both patient care and health care providers' satisfaction. These findings and the current burden of chronic and seasonal diseases call for the real consideration of IPE among national health care colleges.

\section{References}

Al-Nozha, M. M., Al-Maatouq, M. A., Al-Mazrou, Y. Y., Al-Harthi, S. S., Arafah, M. R., Khalil, M. Z. et al. (2004). Diabetes Mellitus in Saudi Arabia. Saudi Medical Journal, 25, 1603-1610.

An RCN Literature Review. Royal College of Nurses (2007). The Impact and Effectiveness of Interprofessional Education in Primary Car. An RCN Literature Review. Royal College of Nurses. 1-28.

Barker, K. K., Bosco, C., \& Oandasan, I. F. (2005). Factors in implementing interprofessional education and collaborative practice initiatives: Findings from key informant interviews. Journal of Interprofessional Care, 19, 166-176

Barr, H. (2002). Interprofessional Education. Chapter 24. Educational Strategies. http://www.nvmo.nl/resources/js/tinymce/plugins/imagemanager/files/20120926_HFDS24boekXX-2002_Barr-H_Interpro fessional_Education.pdf\#page=29

Blue, V., Mitcham, M., Smith, T., Raymond, J., \& Greenbaum, R. (2010). Changing the Future of Health Professions: Embedding Interprofessional Education within an Academic Health Center. Academic Medicine, 85, 1290-1295. http://dx.doi.org/10.1097/ACM.0b013e3181e53e07

Bridges, D. R., Davidson, R. A., Odegard, P. S., Maki, I. V., \& Tomkowiak, J. (2011). Interprofessional Collaboration: Three Best Practice Models of Interprofessional Education. Medical Education Online, 16, 6035. http://dx.doi.org/10.3402/meo.v16i0.6035

Buring, S. M., Bhushan, A., Broeseker, A., Conway, S., Duncan-Hewitt, W., Hansen, L. et al. (2009). Interprofessional Education: Definitions, Student Competencies, and Guidelines for Implementation. American Journal of Pharmaceutical Education, 73, Article 59. http://dx.doi.org/10.5688/aj730459

Canadian Interprofessional Health Collaborative (CIHC) (2014). http://www.cihc.ca/

Hall, P., \& Weaver, L. (2001). Interdisciplinary Education and Teamwork: A Long and Winding Road. Medical Education, 35, 867-875. http://dx.doi.org/10.1046/j.1365-2923.2001.00919.x

Hammick, M. (2000). Interprofessional Education: Evidence from the Past to Guide the Future. Medical Teacher, 22, 461467. http://dx.doi.org/10.1080/01421590050110713

Hammick, M., Freeth, D., Koppel, I., Reeves, S., \& Barr, H. (2007). A Best Evidence Systematic Review of Interprofessional Education: BEME Guide no. 9. Medical Teacher, 29, 735-751. http://dx.doi.org/10.1080/01421590701682576

Hojat, M., Nasca, T. J., Cohen, M. J., Fields, S. K., Rattner, S. L., Griffiths, M. et al. (2001). Attitudes toward Physician-Nurse Collaboration: A Cross-Cultural Study of Male and Female Physicians and Nurses in the United States and 
Mexico. Nursing Research, 50, 123-128. http://dx.doi.org/10.1097/00006199-200103000-00008

Horsburgh, M., Lamdin, R., \& Williamson, E. (2001). Multiprofessional Learning: The Attitudes of Medical, Nursing and Pharmacy Students to Shared Learning. Medical Education, 35, 876-883. http://dx.doi.org/10.1046/j.1365-2923.2001.00959.x

Humphris, D. (2007). Multiprofessional Working, Interprofessional Learning and Primary Care: A Way Forward? Contemporary Nurse, 26, 48-55. http://dx.doi.org/10.5172/conu.2007.26.1.48

Julio, F., Chen, L., Bhutta, Z. A., Cohen, J., Crisp, N., Evans, T. et al. (2010). Health Professionals for a New Century: Transforming Education to Strengthen Health Systems in an Interdependent World. The Lancet, 376, 1923-1958. http://dx.doi.org/10.1016/S0140-6736(10)61854-5

Levisohn, D. (2003). CHMS. Council of Heads of Medical Schools and Dean of UK Faculty’s Position Paper. Interprofessional Education. http://www.medschools.ac.uk/AboutUs/Projects/Documents/Interprofessional\%20Education.pdf

Lumague, M., Morgan, A., Mak, D., Hanna, M., Kwong, J., Cameron, C. et al. (2006). Interprofessional Education: The Student Perspective. Journal of Interprofessional Care, 20, 246-253. http://dx.doi.org/10.1080/13561820600717891

Mandy, A., Milton, C., \& Mandy, P. (2004). Professional Stereotyping and Interprofessional Education. Learning in Health and Social Care, 3, 154-170. http://dx.doi.org/10.1111/j.1473-6861.2004.00072.x

Middle East Respiratory Syndrome Coronavirus (MERS-CoV)—Saudi Arabia. http://www.who.int/csr/don/archive/country/sau/en/

Mires, G., Williams, F., Harden, R., \& Howie, P. (2001). The Benefits of a Multiprofessional Education Programme Can Be Sustained. Medical Teacher, 23, 300-304. http://dx.doi.org/10.1080/01421590120043099

Oandasan, I., \& Reeves, S. (2005). Key Elements for Interprofessional Education. Part 1: The Learner, the Educator and the Learning Context. Journal of Interprofessional Care, 19, 21-38. http://dx.doi.org/10.1080/13561820500083550

Olenick, M., Allen, L. R., \& Smego Jr., R. A. (2010). Interprofessional Education: A Concept Analysis. Advances in Medical Education and Practice, 1, 75-84.

Ponzer, S., Hylin, U., Kusoffsky, A., Lauffs, M., Lonka, K., Mattiasson, A. C., \& Nordström, G. (2004). Interprofessional Training in the Context of Clinical Practice: Goals and Students' Perceptions on Clinical Education Wards. Medical Education, 38, 727-736. http://dx.doi.org/10.1111/j.1365-2929.2004.01848.x

Reeves, S., Zwarenstein, M., Goldman, J., Barr, H., Freeth, D., Hammick, M. et al. (2013). Interprofessional Education: Effects on Professional Practice and Health Care Outcomes. Cochrane Database of Systematic Reviews, 3, CD002213.

Remington, T. L., Foulk, M. A., \& Williams, B. C. (2006). Evaluation of Evidence for Interprofessional Education. American Journal of Pharmaceutical Education, 70, 66.

Sweet, S. J., \& Norman, I. (1995). The Nurse-Doctor Relationship: A Selective Literature Review. Journal of Advanced Nursing, 22, 165-170. http://dx.doi.org/10.1046/j.1365-2648.1995.22010165.x

Thistle Thwaite, J. (2012). Interprofessional Education: A Review of Context, Learning and the Research Agenda. Medical Education, 46, 58-70. http://dx.doi.org/10.1111/j.1365-2923.2011.04143.x

WHO (2014). Framework for Action on Interprofessional Education \& Collaborative Practice. WHO 2010. http://whqlibdoc.who.int/hq/2010/WHO_HRH_HPN_10.3_eng.pdf 
Scientific Research Publishing (SCIRP) is one of the largest Open Access journal publishers. It is currently publishing more than 200 open access, online, peer-reviewed journals covering a wide range of academic disciplines. SCIRP serves the worldwide academic communities and contributes to the progress and application of science with its publication.

Other selected journals from SCIRP are listed as below. Submit your manuscript to us via either submit@scirp.org or Online Submission Portal.
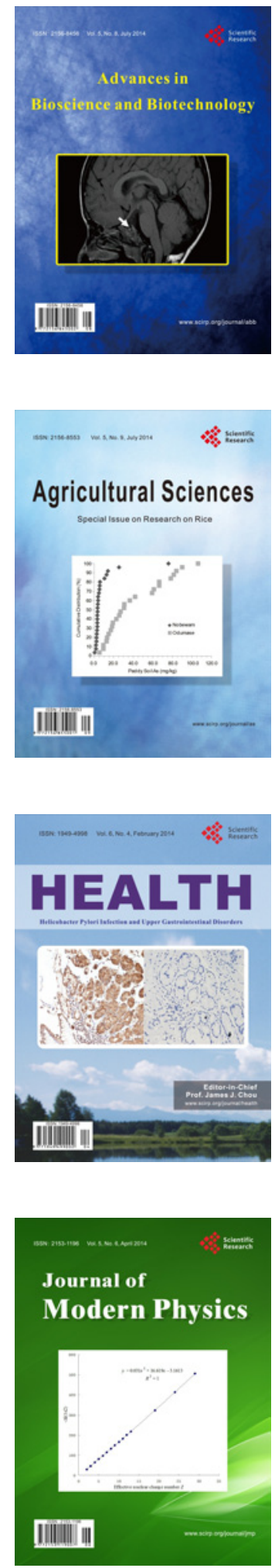
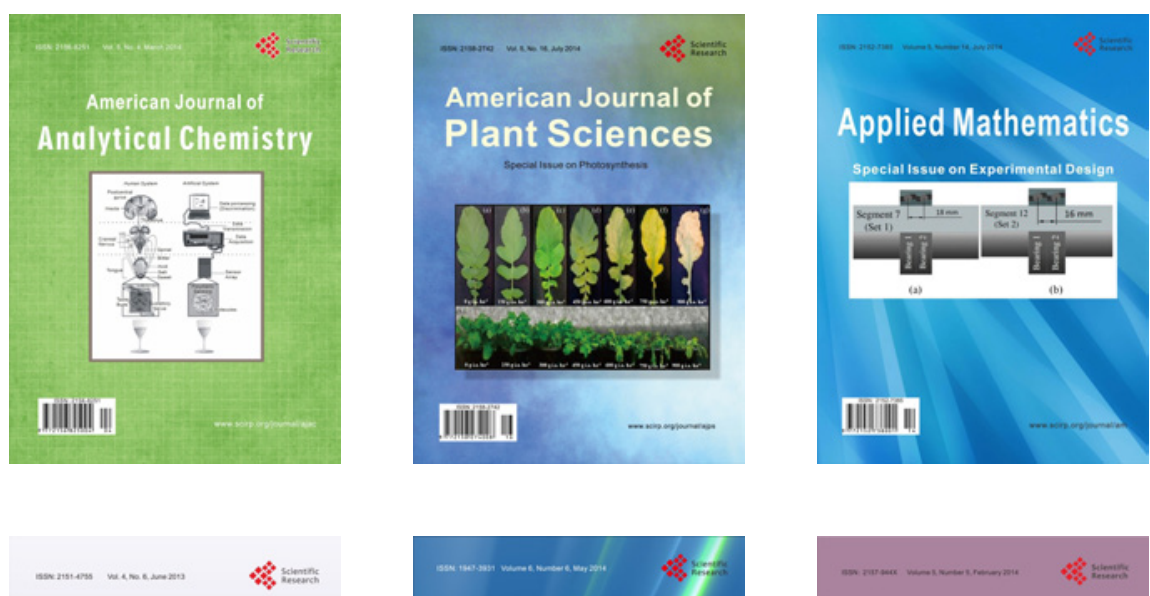

Creative Education
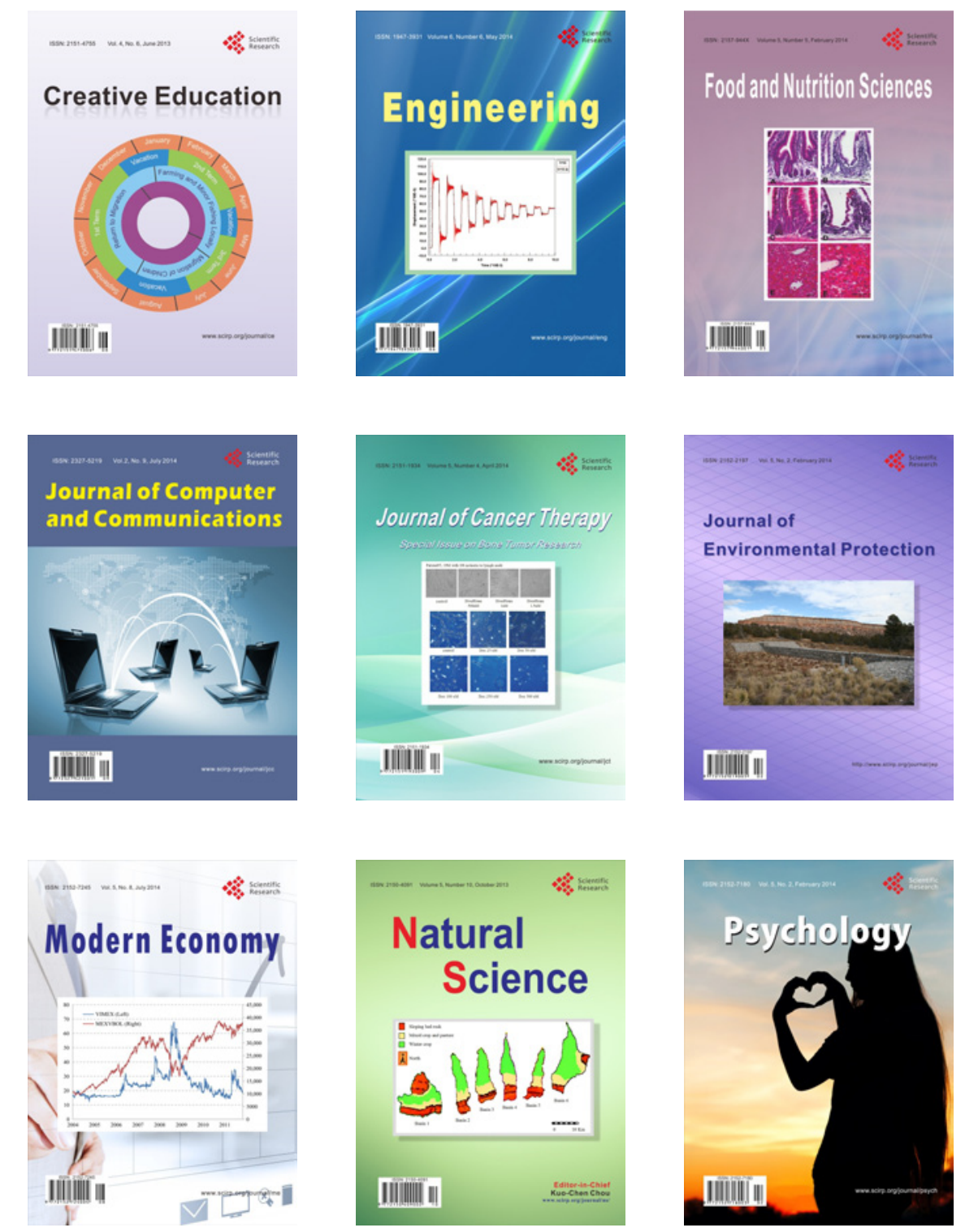